\title{
Capturing Profitability in Asset Pricing Models for Japanese Equities 1994-2016
}

\author{
Dong Liu ${ }^{1} \&$ Hiroshi Yadohisa ${ }^{2}$ \\ ${ }^{1}$ Graduate School of Faculty of Culture and Information Science, Doshisha University, Kyoto, Japan \\ ${ }^{2}$ Graduate School of Faculty of Culture and Information Science, Doshisha University, Kyoto, Japan \\ Correspondence: Dong Liu, Graduate School of Faculty of Culture and Information Science, Doshisha \\ University, Kyoto, Japan. Tel: 81-80-4767-8702. E-mail: liudong1921@ gmail.com
}

Received: January 23, 2018

Accepted: April 24, 2018

Online Published: April 28, 2018

doi:10.5539/ijef.v10n5p254

URL: https://doi.org/10.5539/ijef.v10n5p254

\begin{abstract}
We follow Ball et al. (2015) to investigate and compare firms' gross profit, operating profit, and net income as predictors of returns for a cross-section of traded Japanese equities spanning 1994-2016. We test the predictive power of profit measures on cross-sectional stock returns using portfolio tests and Fama-MacBeth regressions, find that gross-profit-to-book-equity significantly predict returns on sampled stocks. Consistent with Novy-Marx (2013), we also find that sorting portfolios by gross profitability and book-to-market ratios outperform in the Japanese market. Hence, we create a Market-Profitability-Value model that captures value and profitability premium among returns of sampled stocks. Based on Gibbons-Ross-Shanken test and economic value, we demonstrate that our enhanced model outperforms Fama-French multiple-factor model in isolating influences on equity returns.
\end{abstract}

Keywords: expected return, gross profitability, operating profitability, net income

\section{Introduction}

The question of what drives stock returns is perennial in modern finance. The Fama-French $(1992,1993)$ three-factor model has been the benchmark to explain expected returns during the past two decades because the book-to-market ratio (a measure of Value) and market capitalization (Size) have strong explanatory power in empirical analysis. Nonetheless, profitability effects have attracted attention of researchers seeking to explain cross-sectional variations in stock returns. Researchers attend to profitability effects because they can be used to assess the quality of firms and investment decisions.

This study originates with Novy-Marx (2013), who shows that gross profitability relates significantly to stock returns after controlling for book-to-market ratio. Profitability earns a high positive premium and helps to capture most asset-pricing anomalies that plague the Fama-French (1993) three-factor model. Fama and French (2015) add operating profitability to create a five-factor model that outperforms their three-factor model in explaining cross-sections of stock returns. Ball et al. $(2015,2016)$ present a more refined test for profitability effects. First, they re-evaluate whether gross profitability has greater predictive power over returns than net income and operating profitability. Second, they compare the effects of gross profitability, operating profitability, and net income using identical denominators (book value of total assets, book equity, and market capitalization).

These studies show that profitability exerts power in predicting returns among US equities, but scant literature investigates Japanese equities. First, retesting Fama-French's five-factor model by examining years of monthly data for shares on the first and second sections of the Tokyo Stock Exchange (TSE), Kuboda and Takehara (2017) find that operating profitability is not a statistically significant predictor of Japanese equity returns. Maeda (2017) tests q-factor (Note 1) model (market, profitability, and investment), finds that profitability (net income) is not a significant predictor of returns on Japanese equities.

These studies, however, merely retest whether an asset-pricing model is appropriate for the Japanese market. By ignoring profitability effects their conclusions lack force. This study resolves this deficiency in earlier literature. We characterize firms' profits comprehensively using gross profit, operating profit, and net income to assure robustness in predicting equity returns. We confirm that gross-profit-to-book-equity is a superior proxy for predicting equity returns. Our results endorse those of Novy-Marx (2013) and support existence of a gross 
profitability premium for Japanese equities. In addition, we mirror Fama-French three-factor (1993) and five-factor models (2015), delete the redundant factor, and create a Market-Profitability-Value (MKT-RMW-HML) model to explain expected returns on Japanese equities.

This paper proceeds follows. Section 2 describes our data and variable. Section 3 presents methods and empirical results. Section 4 concludes.

\section{Data and Variable}

Financial statement data are from the FactSet database (Note 2). Empirical research covers Japanese equities listed on the first section of the Tokyo Stock Exchange(TSE) that have usable data during 1994-2016 (260 months). Financial firms (industry codes: 7050, 7010, 7100, and 7150) are excluded for their distinctive high-leverage/low-equity capital structures. Our samples cover 834 companies in 1994, and, adjusted yearly, reach 1,658 in 2016 .

To construct factors that might influence equity returns, we assemble annual financial statement data for sales ( $S A L E)$, cost of goods sold (COGS), sales-general-administrative expenses ( $S G A)$, book value of total assets ( $A T$ ), and book equity $(B E)$ measured as $A T$ minus total liabilities $(L T)$. We measure investment patterns $(I N V)$ as changes in total assets $(A T)$ every year. $\log (M E)$ is the $\log$ of market capitalization $(M E)$. $B / M$ indicates the book-to-market ratio $(B E / M E)$. Gross profit $(G P)$ is $S A L E$ minus $C O G S$. Operating profit $(O P)$ is $S A L E$ minus $C O G S$ and $S G A$. Bottom-line profit $(N P)$ is net income.

\section{Methods and Empirical Results}

\subsection{Fama-MacBeth Univariate Regressions on Measures of Profitability}

We use monthly Fama and MacBeth (1973) cross-sectional regressions to examine whether profitability convincingly forecasts stock returns.

Table 1. Fama-MacBeth univariate regressions of firm returns 1994-2016

\begin{tabular}{|c|c|c|c|c|c|c|c|c|c|}
\hline \multirow[t]{2}{*}{ variables } & 1 & 2 & 3 & 4 & 5 & 6 & 7 & 8 & 9 \\
\hline & \multicolumn{3}{|c|}{ Sort by profit/ total assets } & \multicolumn{3}{|c|}{ Sort by profit/ book equity } & \multicolumn{3}{|c|}{ Sort by profit/ market capitalization } \\
\hline GP & 0.45 & & & 0.1 & & & 0.47 & & \\
\hline (t) & $(0.99)$ & & & $(2.09)$ & & & $(3.62)$ & & \\
\hline $\mathrm{OP}$ & & -0.52 & & & -0.24 & & & 1.18 & \\
\hline (t) & & $-(0.25$ & & & $-(0.83$ & & & $(2.71)$ & \\
\hline NP & & & -1.57 & & & -0.62 & & & -0.02 \\
\hline (t) & & & $(-0.58)$ & & & $(-2.13)$ & & & $(-0.03)$ \\
\hline
\end{tabular}

Slope coefficients $(\times 100) \beta$ and (t-statistics) from regressions are shown. To assess profitability as a predictive measure we first focus on its numerator. Deflating $G P, O P$, and $N P$ individually by total asset, book equity, and market capitalization, respectively. Our sample period starts in August 1994 and ends in March 2016.

Table 1 shows regressed monthly returns of individual stocks on lagged profitability. We focus on t-values to compare the explanatory power of measures of profitability.

Deflating by total assets, $G P, O P$, and $N P$ have no significant predicting power, while deflating by book equity, $G P$ and $N P$ have significant predicting power.

Deflating by market capitalization, $G P$ and $O P$ also have power in predicting return significant. Note, however, we admit that a market capitalization-based measure conflates a productivity proxy with $B / M$ ratios. Hence, based on empirical tests for the sampled equities, we choose profit deflated by book equity as a proxy variable.

\subsection{Fama-MacBeth Multivariate Regression}

Table 2 reports model (1)-(3) specifications for multivariate regressions including controls for book-to-market ratio $(B / M)$, size $(\log (\mathrm{ME}))$, and $I N V$ (investment patterns). When controlled accordingly, the $B / M$ is strong for the sampled equities. We reconfirm the existence of strong value effects among Japanese equities per Kuboda and Takehara $(2007,2018)$. The size premium sheds predictive power. Investment patterns show no effect on returns of sampled equities, consistent with Kuboda and Takehara (2017) and unlike US equities. 
Table 2. Fama-MacBeth multivariate regressions of firm returns 1994-2016

\begin{tabular}{cccc}
\hline variables & Model (1) & Model (2) & Model (3) \\
\hline$G P$ & 0.19 & & \\
$(\mathbf{t})$ & $(3.98)$ & & \\
$O P$ & & 0.15 & \\
$(\mathbf{t})$ & & $(0.59)$ & -0.51 \\
$N P$ & & & $(-1.99)$ \\
$(\mathbf{t})$ & & & 0.48 \\
$I N V$ & 0.37 & 0.26 & $(1.37)$ \\
$(\mathbf{t})$ & $(1.03)$ & $(0.7)$ & 0.38 \\
$B / M$ & 0.43 & 0.37 & $(3.36)$ \\
$(\mathbf{t})$ & $(3.53)$ & $(3.24)$ & -0.04 \\
$\log (M E)$ & -0.02 & -0.05 & $(-0.63)$ \\
$(\mathbf{t})$ & $(-0.34)$ & $(-0.73)$ &
\end{tabular}

Multivariate slope coefficients $(\times 100) \beta$ s and (t-statistics) from regressions are shown. We estimate regressions monthly spanning August 1994 to March 2016. t-statistics are based on the time-series variability of slope estimates, incorporating a white adjust for possible autocorrelation in the slopes. Fiscal year-end for more than $90 \%$ of firms in the TSE first section is March 31. Accordingly, sampled firms were sorted at the end of August each year, five months after fiscal year-end, to assure public availability.

$G P$ exhibits significant power to predict returns, whereas the predictive power of $O P$ is not significant. Results show $N P$ has negative power to explain returns, however, motivated by valuation theory, Fama and French (2006) explore the positive relation between profitability and expected returns. Hence, we abandon net income as an investigative variable.

Based on Fama and MacBeth cross-sectional regressions, gross-profit-to-book-equity exerts the most significant power over excepted returns alone or when controlled for size, $B / M$, and $I N V$. Novy-Marx (2013) concludes that gross profit is the cleanest accounting measure of true economic profitability and therefore outperforms other measures of profitability. Items farther down the income statement are more attenuated measures of profitability and less cogent with respect to true economic profitability.

\subsection{Sorts on Profitability}

We perform portfolio tests as a more predictive exercise that escapes bias of Fama and MacBeth regression. We compare results of gross-profit-to-book-equity, and operating-profit-to-book-equity for the sampled equities.

Table 3. Sorts on gross and operating profitability 1994-2016

\begin{tabular}{|c|c|c|c|c|c|c|c|c|c|c|c|}
\hline \multirow[b]{3}{*}{ Portfolio } & \multicolumn{6}{|c|}{ Sort by gross profit / book equity } & \multicolumn{5}{|c|}{ Sort by operating profit / book equity } \\
\hline & \multirow{2}{*}{$\begin{array}{l}\text { Excess } \\
\text { return }\end{array}$} & \multicolumn{4}{|c|}{ Fama-French-three-factor model } & \multirow[b]{2}{*}{ Portfolio } & \multirow{2}{*}{$\begin{array}{l}\text { Excess } \\
\text { return }\end{array}$} & \multicolumn{4}{|c|}{ Fama-French-three-factor model } \\
\hline & & $\alpha$ & $S M B$ & $H M L$ & MKT & & & $\alpha$ & $S M B$ & $H M L$ & $M K T$ \\
\hline 1 (low) & 0.13 & -0.03 & 0.07 & 0.02 & 1.00 & 1 (low) & 0.23 & -0.07 & 0.47 & 0.25 & 1.11 \\
\hline (t) & $(0.39)$ & $(-0.27)$ & $(2.07)$ & (0.63) & (44.47) & (t) & $(0.58)$ & $(-0.39)$ & (9.7) & $(4.72)$ & (34.19) \\
\hline 2 & 0.14 & -0.10 & -0.07 & 0.10 & 0.96 & 2 & 0.21 & -0.01 & 0.03 & 0.07 & 1.03 \\
\hline (t) & $(0.42)$ & $(-1.06)$ & $(-2.48)$ & (3.28) & (52.98) & (t) & $(0.58)$ & $(-0.06)$ & $(0.86)$ & (1.73) & (39.4) \\
\hline 3 & 0.17 & 0.01 & 0.02 & 0.02 & 0.93 & 3 & 0.10 & -0.13 & -0.04 & 0.10 & 0.95 \\
\hline (t) & $(0.55)$ & $(0.11)$ & $(0.77)$ & $(0.81)$ & (57.55) & (t) & $(0.32)$ & $(-1.38)$ & $(-1.5)$ & (3.35) & (53.36) \\
\hline 4 & 0.09 & -0.23 & 0.04 & 0.22 & 1.00 & 4 & 0.15 & -0.07 & -0.05 & 0.10 & 0.91 \\
\hline (t) & $(0.27)$ & $(-2.78)$ & (1.83) & (8.39) & (63.43) & (t) & $(0.5)$ & $(-0.84)$ & $(-1.81)$ & (3.55) & (54.55) \\
\hline 5 & 0.24 & 0.23 & 0.06 & -0.19 & 1.08 & 5 & 0.16 & 0.15 & 0.00 & -0.19 & 1.06 \\
\hline$(t)$ & (0.64) & (2.06) & (1.97) & $(-5.67)$ & (52.24) & (t) & $(0.45)$ & (1.38) & $(0.15)$ & $(-5.89)$ & $(52.78)$ \\
\hline High-Low & 0.10 & 0.26 & -0.01 & -0.22 & 0.08 & High-Low & -0.07 & 0.22 & -0.47 & -0.45 & -0.06 \\
\hline (t) & $(0.56)$ & (1.41) & $(-0.17)$ & $(-3.81)$ & (2.34) & (t) & $(-0.26)$ & $(0.89)$ & $(-6.87)$ & $(-5.97)$ & $(-1.25)$ \\
\hline
\end{tabular}

Table 3 reports value-weighted excess returns and three-factor model alphas and $M K T, S M B$ and $H M L$ loadings. The "High-Low" profitability spread portfolio is computed as long the highest profitability decile and short the lowest decile. We sort stocks into deciles based on TSE first section breakpoints at the end of each March and hold the portfolio for the August. Our sample period starts in August 1994 and ends in March 2016.

In the $G P$ formulation, sorting portfolios' average excess returns are generally increasing with $G P$. Alphas for the Fama-French-three-factor model increase with GP, although not monotonically. The high-minus-low quintile portfolio earns a statistically insignificant average excess return of 10 basis points per month ( $\mathrm{t}$-value $=$ 0.56). Alpha for the three-factor model is 26 basis points per month ( $\mathrm{t}$-value $=1.41$ ). Loading for $H M L$ is negative significant. That reveals high gross-profit-to-book-equity portfolio generates more excess returns, meanwhile there exists negative relation between $G P$ and $B / M$ ratio. 
In the $O P$ formulation, in contrast with $G P$, the high-minus-low quintile portfolio does not spread excess returns. In fact, comparison reveals that a strategy of pursuing gross profitability generates more excess returns than pursuing operating profitability.

\subsection{Construction of Mimicking Factors}

Based on Novy-Marx (2013) and results for Table 3, we find that gross profitability is negatively correlated with book-to-market ratio. That reveals the profitability strategy is a growth strategy, and it provides a great hedge for value strategies. We can explore the performance of portfolios double-sorted by profitability and $B / M$ ratio to generate more excess return.

For comparison, we sort $G P-B / M$ portfolios, $O P-B / M$ portfolios, Size-GP portfolios, and Size-OP portfolios for the sampled equities. Average excess portfolio returns appear.

Table 4 Panel A. Double sort by profitability and $B / M$

\begin{tabular}{|c|c|c|c|c|c|c|c|c|c|c|c|c|c|c|c|}
\hline & Weak & 2 & 3 & 4 & Robust & $R-W$ & (t) & & Weak & 2 & 3 & 4 & Robust & $R-W$ & (t) \\
\hline$B / M$ & & & GP quitiles & & & & & $B / M$ & & & OP quitiles & & & & \\
\hline Low & 0.16 & -0.04 & -0.04 & -0.19 & 0.04 & -0.13 & $(-0.42)$ & Low & 0.09 & -0.27 & 0.03 & 0.02 & -0.02 & -0.12 & $(-0.21)$ \\
\hline 2 & -0.03 & 0.02 & 0.18 & 0.16 & 0.47 & 0.50 & $(2.23)$ & 2 & -0.06 & 0.03 & 0.14 & 0.09 & 0.65 & 0.71 & $(2.05)$ \\
\hline 3 & 0.13 & 0.18 & 0.33 & 0.50 & 0.82 & 0.69 & (2.73) & 3 & 0.47 & 0.17 & 0.24 & 0.71 & 0.43 & -0.03 & $(-0.09)$ \\
\hline 4 & 0.39 & 0.49 & 0.70 & 0.73 & 0.88 & 0.49 & (1.89) & 4 & 0.52 & 0.60 & 0.76 & 0.61 & 0.69 & 0.17 & $(0.56)$ \\
\hline High & 0.55 & 1.04 & 1.10 & 1.17 & 1.37 & 0.82 & (2.41) & High & 0.77 & 0.80 & 0.92 & 1.26 & 1.37 & 0.61 & (1.34) \\
\hline$H-L$ & 0.39 & 1.09 & 1.14 & 1.36 & 1.33 & & & $H-L$ & 0.67 & 1.07 & 0.88 & 1.24 & 1.40 & & \\
\hline (t) & $(0.82)$ & $(2.62)$ & (3.12) & (3.55) & $(2.57)$ & & & (t) & (1.13) & (2.02) & (1.97) & $(2.67)$ & (2.19) & & \\
\hline
\end{tabular}

Panel A shows average excess returns for 25 value-weighted (VW) portfolios, from independent ( $5 \times 5 G P-B / M$ sorting), and (5x5 $O P$ - $B / M$ sorting). The "R-W" profitability spread portfolio is computed as long the most robust profitability decile and short the weakest decile. The "H-L" profitability spread portfolio is computed as long the highest $B / M$ decile and short the lowest decile. We sort stocks into deciles based on TSE first section breakpoints at the end of each March and hold the portfolio for the August. Our sample period starts in August 1994 and ends in March 2016.

In the $G P-B / M$ formulation, except in row $1, G P$ and average return are positively related in all remaining rows. $\mathrm{R}-\mathrm{W}$ portfolios (gross profitability premium) in rows 3 and 5 are significant. Value premium is evident in columns 2 through 5. Large value and robust profitability portfolios perform best with $1.37 \%$ monthly returns. We confirm that controlling for $G P$ improves performance of value strategies and controlling for $B / M$ ratio improves performance of profitability strategies.

In the $O P-B / M$ formulation, the R-W portfolio (operating profitability premium) is positive in rows $2,4,5$. However, only in row 2 is significant. Value premium is effective in columns 2 through 4.

Panel A suggest that $G P$ quintiles outperform $O P$ quintiles.

Table 4 Panel B. Double sort by profitability and size

\begin{tabular}{|c|c|c|c|c|c|c|c|c|c|c|c|c|c|c|c|}
\hline & Weak & 2 & 3 & 4 & Robust & $R-W$ & (t) & & Weak & 2 & 3 & 4 & Robust & $R-W$ & (t) \\
\hline Size & & & GP quitiles & & & & & Size & & & $O P$ quitiles & & & & \\
\hline Small & 0.66 & 0.60 & 0.72 & 0.81 & 0.85 & 0.19 & $(1.07)$ & Small & 0.78 & 0.54 & 0.66 & 0.77 & 0.83 & 0.05 & $(0.23)$ \\
\hline 2 & 0.34 & 0.28 & 0.31 & 0.33 & 0.31 & -0.03 & $(-0.19)$ & 2 & 0.33 & 0.33 & 0.28 & 0.27 & 0.35 & 0.01 & $(0.07)$ \\
\hline 3 & 0.15 & 0.22 & 0.18 & 0.26 & 0.33 & 0.18 & $(1.07)$ & 3 & 0.17 & 0.22 & 0.23 & 0.31 & 0.20 & 0.03 & $(0.14)$ \\
\hline 4 & 0.06 & 0.16 & 0.17 & 0.38 & 0.38 & 0.32 & (1.89) & 4 & 0.22 & 0.26 & 0.18 & 0.14 & 0.31 & 0.09 & $(0.63)$ \\
\hline Big & 0.22 & 0.14 & 0.20 & 0.08 & 0.22 & 0.01 & $(0.02)$ & Big & 0.31 & 0.20 & 0.14 & 0.16 & 0.17 & -0.14 & $(-0.47)$ \\
\hline$S-B$ & 0.44 & 0.46 & 0.52 & 0.73 & 0.63 & & & $S-B$ & 0.47 & 0.34 & 0.52 & 0.61 & 0.66 & & \\
\hline$(\mathrm{t})$ & (1.07) & (1.2) & (1.62) & (2.18) & (1.51) & & & (t) & (1.16) & $(0.88)$ & (1.51) & (1.96) & (1.67) & & \\
\hline
\end{tabular}

Panel B shows average excess returns for 25 value-weighted (VW) portfolios from independent (5x5 Size-GP sorting), and (5x5 Size-OP sorting). The "R-W" profitability spread portfolio is computed as long the most robust profitability decile and short the weakest decile. The "S-B" profitability spread portfolio is computed as short the biggest size decile and long the smallest decile. We sort stocks into deciles based on TSE first section breakpoints at the end of each March and hold the portfolio for the August. Our sample period starts in August 1994 and ends in March 2016.

In the Size-GP formulation, holding GP roughly constant, average return typically falls as size increases. Only the S-B portfolio (size premium) in column 4 is significant. Holding size roughly constant, average return typically increases with $G P$, but R-W portfolios (gross profitability premium) are not significant. That finding reveals Size-GP sorting underperforms $G P-B / M$ sorting. 
In the Size-OP formulation, holding $O P$ roughly constant, average return typically falls as size increases. Only the S-B portfolio (size premium) in column 4 is significant. Holding size roughly constant, average return typically increases with profitability. No R-W portfolio (operating profitability premium) is significant. That finding reveals Size-OP sorting underperforms $O P-B / M$ sorting.

Overall, Panel B suggest value quintiles outperform size quintiles. Results in Table 4 suggest sorting of $G P$ and $B / M$ portfolios outperform among the sampled equities.

\subsection{Summary of Factor Model}

We eliminate redundant factors to boost the model's explanatory power. Based on Fama-MacBeth regressions and tests of combination portfolios, we define two main factor premiums: $H M L$ (high minus low $B / M$ ) and $R M W$ (robust minus weak $G P$ ). If a characteristic is significant in cross-sectional regressions, we hypothesized that its factor will be significant in time-series regressions. Hence, we created a new model $M K T-R M W(G P)-H M L$ model for the sampled equities and compared time-series regressions with the Fama-French-three-factor model. Test factor models are

$$
\begin{aligned}
& R_{i t}-R_{F t}=a_{i}+b_{i}\left(R_{M t}-R_{F t}\right)+s_{i} S M B_{t}+h_{i} H M L_{t}+e_{i t} \\
& R_{i t}-R_{F t}=a_{i}+b_{i}\left(R_{M t}-R_{F t}\right)+h_{i} H M L_{t}+r_{i} R M W(G P)_{t}+e_{i t}
\end{aligned}
$$

Where: $R_{i t}$ is the return of portfolio in month t. $R_{F t}$ is risk free rate. $\alpha_{\mathrm{i}}$ is the intercept, $b_{i}, s_{i}, h_{i}, r_{i}$ are factor coefficients for time-series regression, $e_{i t}$ is the error term.

Following Fama-French (1993, 2015), to construct factor, we sort independently to assign stocks to two size groups, three $B / M$ groups, and three profitability groups $(G P)$. The Size breakpoint is median market cap. $B / M$ or $G P$ breakpoints are the 30th and 70th percentiles.

$M K T(R m-R f)$ is the value-weighted return on the market portfolio of all sampled stocks minus the risk-free rate. $S M B$ is the return on a diversified portfolio of small-cap stocks minus the return on a diversified portfolio of big-cap stocks. $H M L$ is the difference between returns on diversified portfolios of high and low $B / M$ stocks. In addition, $R M W(G P)$ is the difference between returns on diversified portfolios of stocks with robust and weak gross profitability.

\subsection{Evaluating Model Performance}

Gibbons, Ross, and Shanken (1989) propose the most widely used statistical test of empirical validity for asset-pricing models (GRS test). It tests for the null hypothesis that the intercept terms of empirical asset-pricing model portfolios jointly equal 0 . Failure to reject the null hypothesis is evidence the model adequately captures portfolio returns. Meanwhile, considering its predictive power properties, we follow Kim and Shamsuddin (2016), add to economic value to evaluate model performance.

The test models include a Fama-French-three-factor model and our MKT-RMW(GP)-HML factor model. The test samples include $G P-B / M$ portfolios, $O P-B / M$ portfolios, Size-GP portfolios, Size-OP portfolios, Size-B/M portfolios.

Table 5. Gibbons-Ross-Shaken Test (Gibbons et al., 1989; Kim \& Shamsuddin, 2016)

\begin{tabular}{cccc}
\hline Test portfolios & Model & GRS P value & Economic value \\
\hline \multirow{2}{*}{ B/M-GP } & Fama-French-three-factor & 0.02 & 0.51 \\
& MKT-RMW(GP)-HML(B/M) & 0.05 & 0.55 \\
B/M-OP & Fama-French-three-factor & 0.73 & 0.66 \\
& MKT-RMW(GP)-HML(B/M) & 0.75 & 0.68 \\
Size-GP & Fama-French-three-factor & 0.00 & 0.47 \\
& MKT-RMW(GP)-HML $(B / M)$ & 0.00 & 0.48 \\
Size-OP & Fama-French-three-factor & 0.09 & 0.55 \\
& MKT-RMW(GP)-HML $(B / M)$ & 0.13 & 0.58 \\
Size-B/M & Fama-French-three-factor & 0.02 & 0.51 \\
& MKT-RMW(GP)-HML $(B / M)$ & 0.01 & 0.52 \\
\hline
\end{tabular}

Table 5 reports results from the Gibbons-Ross-Shaken test (Gibbons et al., 1989). Comprehensively, the GRS $P$ value indicates statistical significance. The bigger the $P$ value, the greater the model performance. Economic value indicates proportion between the maximum sharpe ratio of the three factor portfolios and the slope of the efficient frontier based on all assets. The bigger the economic value, the greater the dual economic and market efficiency. 
For $G R S P$ value, except $5 \times 5$ Size-B/M sorting portfolios, our $M K T-R M W(G P)-H M L$ factor model outperforms the Fama-French-three-factor model. For economic value, our $M K T-R M W(G P)-H M L$ model always provides optimum. Overall, we show our $M K T-R M W(G P)-H M L$ model outperforms both the statistical and economic significance for the sampled equities.

\section{Conclusion}

McLean and Pontiff (2016) argue that some stock market anomalies are less anomalous after being published. Repeatedly cited size and value factors naturally are less anomalous over time. That also impels us to seek new effective factors and new-factor models. Our conclusions are as follows.

We find that gross profitability surpasses operating profitability and net income in power to predict returns on the sampled equities. This finding explains why Kuboda and Takehara (2017) and Maeda (2017) say profitability is not a significant factor in the Japanese equity market: they choose a flawed proxy for profitability.

As a measure of profitability, gross-profit-to-book-equity better explains the sampled cross-section of expected returns than operating profitability and net income. We extend Novy-Marx's (2013) intuition about focusing on gross profitability rather than current revenue and construct a measure of gross profit with a stronger link to expected returns on Japanese equities.

Size premium for the sampled equities shed predictive power over time and become redundant. Value premium remain strong among our sampled equities. Hence, we created a new $M K T-R M W(G P)-H M L$ factor model and investigated the applicability of a Fama-French-three-factor model on our sampled equities. Tests reveal that the model featuring gross profitability outperforms the Fama-French-three-factor model.

\section{Acknowledgements}

The authors are grateful to Professors Kato and Isagawa in Kyoto University and the Mizuho Securities Endowment, also thank the participants at the 23th and 25th meetings of the Japan Finance Association. Any errors are our own.

\section{References}

Ball, R., Gerakos, J., Linnainmaa, J. T., \& Nikolaev, V. (2016). Accruals, cash flows, and operating profitability in the cross section of stock returns. Journal of Financial Economics, 121(1), 28-45. https://doi.org/10.1016/j.jfineco.2016.03.002

Ball, R., Gerakos, J., Linnainmaa, J. T., \& Nikolaev, V. V. (2015). Deflating profitability. Journal of Financial Economics, 117(2), 225-248. https://doi.org/10.1016/j.jfineco.2015.02.004

Fama, E. F., \& French, K. R. (1992). The Cross Section of Expected Stock Returns. Journal of Finance, 47, 427-465. https://doi.org/10.1111/j.1540-6261.1992.tb04398.x

Fama, E. F., \& French, K. R. (1993). Common Risk Factors in the Returns on Stocks and Bonds. Journal of Financial Economics, 33, 3-56. https://doi.org/10.1016/0304-405X(93)90023-5

Fama, E. F., \& French, K. R. (2006). Profitability, investment, and average returns. Journal of Financial Economics, 82, 491-518. https://doi.org/10.1016/j.jfineco.2005.09.009

Fama, E. F., \& French, K. R. (2015). A five-factor asset- pricing model. Journal of Financial Economics, 116, 1-22. https://doi.org/10.1016/j.jfineco.2014.10.010

Gibbons, M. R., Ross, S. A., \& Shanken, J. (1989). A Test of the Efficiency of a Given Portfolio. Econometrics, 57, 1121-1152. https://doi.org/10.2307/1913625

Kim, J. H., \& Shamsuddin, A. (2016). Reappraising empirical validity of asset-pricing models with consideration of statistical power. Social Science Electronic Publishing. https://doi.org/10.2139/ssrn.2851370

Kubota, K., \& Takehara, H. (2007). Fama-French Factor Model no YuKo-sei no Sai-kensho. Gendai Finance, 22, $3-23$.

Kubota, K., \& Takehara, H. (2018). Does the Fama and French Five-Factor Model Work Well in Japan? International Review of Finance, (1). https://doi.org/10.1111/irfi.12126

Maeda, B. A. (2017). Application of the q-Factor Model to the Japanese Share Market. International Journal of Economics and Finance, 9(6), 15. https://doi.org/10.5539/ijef.v9n6p15

McLean, R. D., \& Pontiff, J. (2016). Does academic research destroy stock return predictability? Journal of Finance, $71(1), 5-32$. https://doi.org/10.1111/jofi.12365 
Novy-Marx, R. (2013). The other side of the value: The gross profits-to-assets premium. Journal of Financial Economics, 108, 1-28. https://doi.org/10.1016/j.jfineco.2013.01.003

Tobin, J. (1969). A general equilibrium approach to monetary theory. Journal of Money Credit and Banking, 1, 15-29. https://doi.org/10.2307/1991374

\section{Notes}

Note1. $q$-factor, based on $q$-theory (Tobin, 1969) predicts that investment frictions steepen the relation between expected returns and firm investment.

Note 2. FactSet integrates third-party data for $16,000+$ active companies. It provides financial information and analytical applications to global buy and sell-side professionals. FactSet is popular among Japanese financial analysts and portfolio managers and the world's third-largest provider of financial data behind Bloomberg and Thomson Reuters.

\section{Copyrights}

Copyright for this article is retained by the author(s), with first publication rights granted to the journal.

This is an open-access article distributed under the terms and conditions of the Creative Commons Attribution license (http://creativecommons.org/licenses/by/4.0/). 